\title{
INFORMAÇÃO E CIDADANIA \\ NOS ESPAÇOS LIVRES PÚBLICOS
}

\author{
INFORMATION SYSTEM AND CITIZIENSHIP IN OPEN PUBLIC SPACES
}

\author{
Margarida Correia Lima \\ Professora mestra do Departamento de Design da Universidade Federal de Pernambuco (UFPE), \\ Laboratório de Ergonomia e Design Universal (LABERGO Design) \\ margaridacorreialima@yahoo.com.br
}

\author{
Ana Rita Sá Carneiro \\ Professora doutora do Departamento de Arquitetura e Urbanismo da Universidade Federal de Pernambuco \\ (UFPE) e coordenadora do Laboratório da Paisagem \\ anaritacarneiro@hotmail.com
}

\section{Laura Bezerra Martins}

Professora doutora do Departamento de Design da Universidade Federal de Pernambuco (UFPE), Laboratório de Ergonomia e Design Universal (LABERGO Design)

laurabm@folha.rec.br

\section{RESUMO}

Este artigo trata das diretrizes para elaboração de sistemas de informação para parques e praças, com a finalidade de dotar esses logradouros de elementos informativos: de orientação espacial, de difusão cultural, de educação ambiental, de preservação dos bens públicos, a partir da pesquisa desenvolvida no mestrado em Design, da UFPE, na cidade do Recife. As diretrizes foram definidas levando em conta aspectos teóricos sobre a vivência nos espaços livres públicos e da ergonomia informacional em parques e praças. A pesquisa realizada constatou a relevância de estudos dessa natureza, que enfoquem o espaço público, tendo como ponto norteador a qualidade de vida nas cidades contemporâneas, na intenção de relacionar os campos do design e da arquitetura da paisagem.

Palavras-chave: Sistema de informação, parques e praças, cidadania, ergonomia informacional, informação no espaço público.

\begin{abstract}
This paper deals with the principles for elaborating Information Systems for parks and public squares, with the objective of establishing in these amenities the informational elements of: space orientation, cultural diffusion, environmental education, public property preservation, observing the principles developed in the MSc Research in Design in the UFPE (Federal University of Pernambuco), for the City of Recife. The directions were defined considering the theoretical aspects of life in the free public spaces and informational ergonomics for the parks and public squares. That research established the relevance of the kind of studies which look at the public spaces with the focus on the quality of life in the modern urban environment trying to create a relationship between design studies and landscape architecture.
\end{abstract}

Keywords: Information system, information in the public space, parks and public squares, citizenship, information ergonomics. 


\section{INTRODUÇÃO}

Os processos de urbanização acelerada que geram ocupações desordenadas e o adensamento populacional nas últimas décadas do século XX têm levado ao aumento da importância dos espaços livres públicos, parques e praças, para atenuar os danos que aqueles fenômenos acarretam à qualidade de vida das massas citadinas. Faz-se mister buscar melhoria das condições ambientais para essas populações, proporcionando-Ihes oportunidades e equipamentos de lazer em áreas abertas, de livre acesso e convivência comum.

Nos espaços livres públicos das cidades brasileiras, parques e praças, faltam, muitas vezes, adequação dos projetos paisagísticos às necessidades sociais e culturais da população, assim como características artísticas e ecológicas relacionadas à paisagem local. Isso ocorreu no Recife na década de 1930 com a presença do paisagista Burle Marx, cujos projetos tinham função educativa, explorando temas da vegetação regional e atendendo às necessidades de diferentes faixas etárias da população. No caso do parque do Caiara, Recife-PE, projetado na década de 1990, foram propostos equipamentos não condizentes com a vida da comunidade, tais como: pistas de bicicross e patinação. $\bigcirc$ parque foi implantado, mas não foi incorporado à vida dos moradores e teve parte dele destruído. Esse espaço não tem visibilidade e seu acesso é difícil. Constatou-se, dessa maneira, a não adequação de um projeto àquela área específica.

Por outro lado, percebe-se que as pessoas continuam a demandar espaços de convivência, acolhedores e atraentes, que possam responder a diferentes interesses e conveniência da população citadina e abrigar manifestações afirmativas da cidadania. Os parques e praças são locais propícios para informar o usuário sobre diversos assuntos relacionados a esses próprios espaços e à cidade.

Foi nesse intuito que a pesquisa tomou como objetivo definir diretrizes para elaboração de sistemas de informação para os espaços livres públicos, parques e praças, com a finalidade de dotar esses logradouros de elementos informativos: de orientação espacial, de difusão cultural, de educação ambiental, de preservação dos bens públicos em benefício dos usuários.

A pesquisa foi realizada no período de março de 2004 a julho de 2006, na cidade do Recife, estado de Pernambuco, na região nordeste do Brasil.

A primeira parte da pesquisa empírica foi realizada em 8 (oito) espaços livres públicos, sendo 4 (quatro) parques - 13 de Maio, Jaqueira, Arnaldo Assunção e Robert Kennedy e 4 (quatro) praças - República, Casa Forte, Prof. Barreto Campelo e ABC. $\bigcirc$ parque 13 de Maio e a praça da República se situam no centro da cidade. $\bigcirc$ parque da Jaqueira, no bairro da Jaqueira, e a praça de Casa Forte, no bairro de Casa Forte. Ambos se encontram em bairros residenciais e próximos a bares, restaurantes e shoppings frequentados pela população das classes média e alta. $\bigcirc$ parque Arnaldo Assunção, a praça Professores Barreto Campelo, o parque Robert Kennedy e a praça do $A B C$ são espaços livres públicos de bairros mais periféricos. 
Os aspectos observados e identificados foram: o mobiliário urbano, mais especificamente, a sinalização; o uso efetivo que as pessoas dão àquelas áreas, considerando os elementos simbólicos existentes, analisando o contexto urbanístico em que os espaços estão inseridos, além dos aspectos que poderiam interferir no processo de transmissão das informações.

A segunda parte da pesquisa foi realizada especificamente com os usuários do parque 13 de Maio e da praça da República e com os gestores públicos. Foram aplicados questionários com o objetivo de conhecer, com maior acuidade, o perfil dos usuários, o uso e os problemas relacionados à acessibilidade, segurança, orientação e informações existentes; e ainda, ter conhecimento dos tipos de informações que os usuários desses espaços gostariam que fossem aí veiculados.

As entrevistas com os gestores públicos abordaram questões relacionadas ao planejamento, orçamento, administração e comunicação. Quanto ao planejamento, procurou-se conhecer se os parques e praças atendiam às necessidades dos usuários; em seguida, conhecer as disponibilidades orçamentárias, parcerias e programações destinadas para essas áreas; identificar os fatores facilitadores e limitadores da administração dos parques e praças, e, finalmente, confrontar a visão dos gestores públicos envolvidos com os espaços livres públicos, parques e praças, com as opiniões dos usuários.

Esta pesquisa tem enfoque no estudo da ergonomia, com ênfase na ergonomia informacional, na ergonomia cognitiva, na ergonomia do ambiente construído e na ergonomia cultural, considerando os princípios de desenho universal e da acessibilidade integral.

Nesse sentido, Castells (1999, p.423) afirma que a era da informação está introduzindo uma nova forma urbana - a cidade informacional. Apesar da diversidade extraordinária dos contextos físicos e culturais, há algumas características comuns fundamentais no desenvolvimento transcultural da cidade informacional. É crescente a convergência de tecnologias específicas para sistemas integrados, facilitando, dessa forma, a comunicação da sociedade e das pessoas.

A convergência de tecnologias é essencial para o processo, como explica Cebrián (1999, p. 145). Diante das técnicas de substituição daquelas com as quais estávamos acostumados - o automóvel substitui a diligência, o avião, o trem de ferro, o fax, o correio ou o telégrafo - o mundo digital provoca a integração de todas elas. Assim, as novas tecnologias podem contribuir para uma revalorização dos espaços livres públicos, parques e praças, utilizando o meio ambiente propício ao desenvolvimento de fontes informacionais da sociedade.

Para o entendimento das diretrizes para elaboração do sistema de informação em parques e praças foi importante apresentar, inicialmente, conceitos sobre o espaço público relacionando função e uso, aspectos da comunicação e ergonomia informacional e dados da pesquisa empírica do parque 13 de Maio e praça da República.

\section{ESPAÇO PÚBLICO: FUNÇÃO E USO}

Nos debates contemporâneos sobre urbanismo e na agenda de políticas de intervenção urbana o tema espaço público é dos mais polêmicos. As concepções atuais 
dominantes sobre espaço público são tributárias do urbanismo moderno, com visão acentuadamente de lugar físico - espaço que tenha uma modalidade de gestão ou propriedade. Carrión (2007, p. 79-97) afirma ser esse um conceito muito restritivo. Argumenta aquele autor que a estrutura urbana se organiza por distintos usos do solo, tendo, o espaço público, a função de vincular uns aos outros (comércio, administração), de criar lugares para recreação (parques e praças), de desenvolver intercâmbio de produtos (centros comerciais, feiras), de adquirir informação, ou de produzir marcos simbólicos e monumentos.

Carrión (2007, p. 79-97) alerta que as concepções modernas dominantes consideram, de forma acentuada, a discussão sobre a propriedade e a apropriação do espaço, pontuando os aspectos: espaço vazio e espaço construído, espaço individual e espaço coletivo e a oposição do espaço privado ao espaço público. No conceito jurídico, o espaço público é o que não é privado, é de todos e é assumido pelo Estado como representante e garantidor do interesse geral, tanto como seu proprietário quanto como administrador. $E$, no conceito filosófico, é um conjunto de núcleos isolados ou interligados no qual se atenua a individualidade e, portanto, restringe-se a liberdade.

Carrión (2007, p. 79-97) introduz um conceito alternativo, afirmando: "O espaço público é um componente fundamental para a organização da vida coletiva (integração, estrutura) e a representação (cultura, política) da sociedade que faz sua razão de ser na cidade e é um dos direitos fundamentais das pessoas na cidade." Acrescenta ele: "O direito ao espaço público é como um direito à inclusão porque é o 'el respecto al derecho ajeno es la paz': la alteridad." (CARRIÓN, 2003) Explica o autor: é no mesmo espaço onde se constrói a tolerância e respeita-se o direito do outro em um convívio pacífico. Portanto, o direito fundamental da cidadania frente à cidade é o direito ao espaço público porque permite construir o direito à identidade e à polis.

Ainda segundo Carrión (2007, p. 79-97), o espaço público cumpre duas funções dentro da cidade: "é um elemento que dá sentido e forma à vida coletiva" mediante um tipo particular de urbanismo em que o público define sua lógica e razão de ser e onde o urbanismo deve ser organizado a partir do público e não do privado, do coletivo e não do individual e mediante o uso coletivo do espaço público, tendo a possibilidade de a população se apropriar da cidade - e que a faça sua - e viver em sociedade. É também - "elemento da representação da coletividade" no qual se dá visibilidade à sociedade porque é ali que se constrói a expressão e a identificação sociais dos diversos.

Nas cidades contemporâneas, os espaços livres públicos são elementos fundamentais da vida urbana. Nesse sentido, dois tipos de espaços livres públicos, parques e praças têm tido funções múltiplas, a serviço da vida coletiva, variando segundo configuração e uso da população em diferentes épocas e lugares. Variam, assim, as funções de tais espaços, assumindo novas configurações, no decorrer do tempo, regidas pelas mudanças sociais.

Sá Carneiro e Mesquita (2000, p. 4), no estudo sobre os espaços livres do Recife (2000), afirmam que o tratamento dado aos parques e praças de uma cidade revela o grau de civilidade de sua população e como aí são exercidas os direitos e deveres 
da cidadania. Sá Carneiro e Mesquita (2000, p. 28) definem parques com base na realidade da cidade do Recife, que reúne 8 (oito) parques urbanos, variando de 2 (dois) a 7 (sete) ha e 219 (duzentos e dezenove) praças, além de 19 (dezenove) unidades de conservação, como espaços livres públicos, com função predominante de recreação, ocupando, na malha urbana, uma área em grau de equivalência superior à da quadra típica urbana, em geral apresentando componentes da paisagem natural - vegetação, topografia, elemento aquático - como também edificações destinadas a atividades recreativas, culturais e/ou administrativas. Ainda definem praças como espaços livres públicos, com função de convívio social, inseridos na malha urbana como elemento organizador da circulação e de amenização pública, com área equivalente à da quadra urbana (aproximadamente $120 \mathrm{~m} \times 120 \mathrm{~m}$ ), geralmente contendo expressiva cobertura vegetal, mobiliário lúdico, canteiros e bancos.

As características urbanas dos parques e praças do Recife são bem diferenciadas, segundo o tipo e a função. Os parques de vizinhança estão inseridos em áreas predominantemente residenciais. Alguns parques e praças mais conhecidos localizam-se em áreas comerciais e do centro administrativo, como o parque 13 de Maio e a praça da República. Outros parques e praças de funções múltiplas - de contemplação, lazer e prática de esportes ou exercícios físicos - situam-se em áreas de uso misto, residenciais e contendo bares e restaurantes (Figura 1).

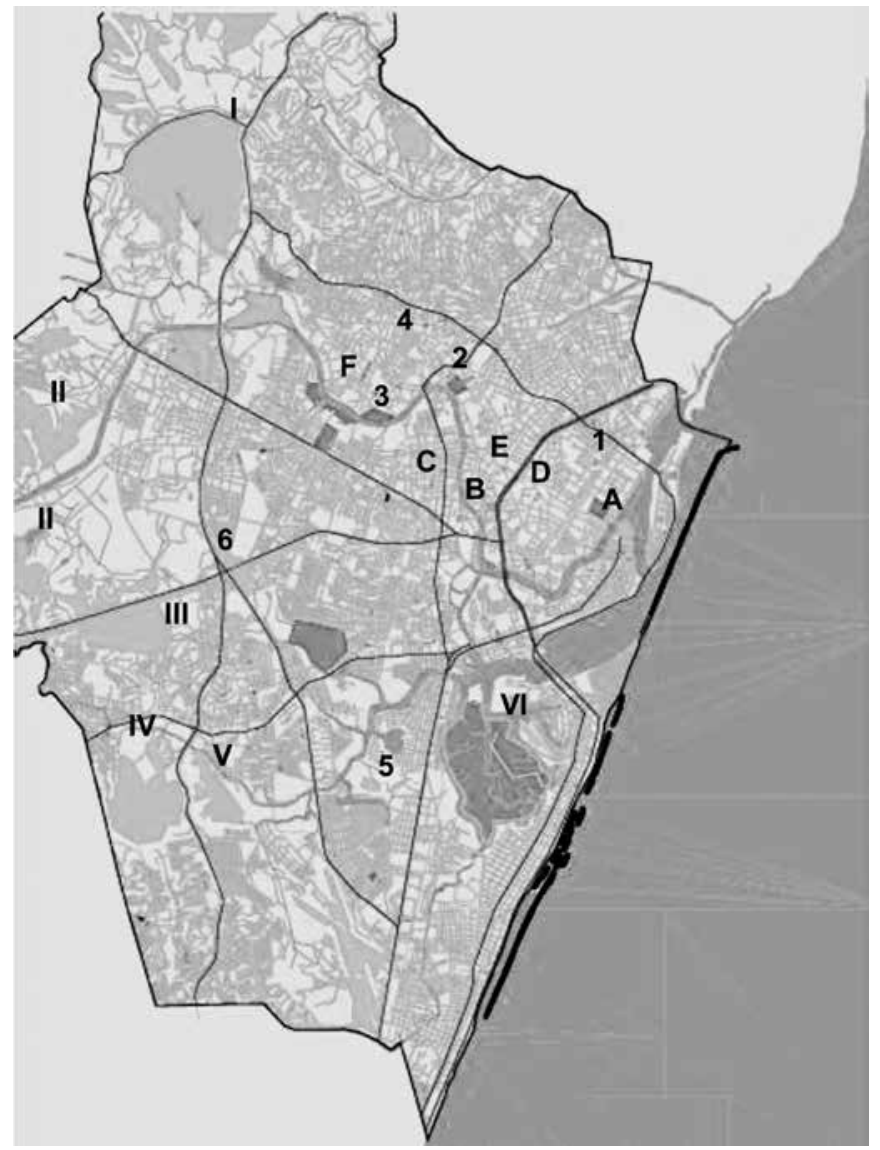

Parques

1. 13 de Maio

2. Jaqueira

3. Santana

4. Areial Velho de

Bom Jesus

5. Robert kennedy

6. Arnaldo Assunção

\section{Praças}

A. República

B. Derby

C. Euclides da Cunha

D. Chora Menino

E. Entroncamento

F. Casa Forte

\section{Unidades de conservação}

I. Guabiraba/Pau Ferro

II. Mata da Várzea

III. Jardim Botânico

IV. Mata do Barro

V. Engenho Uchoa

VI. Parque dos Manguezais

Figura 1: Mapa da cidade do Recife identificando parques, praças e unidades de conservação

Fonte: Laboratório da Paisagem da Pesquisa Paisagem Urbana e Patrimônio no Recife, 2010 
Foram identificadas, nos quatro parques e quatro praças pesquisados, várias funções: de descanso, de lazer, de contemplação, ecológica, turística e de convívio social. Esses espaços públicos, em geral, têm funções múltiplas e contêm equipamentos de ginástica, pistas de cooper e brinquedos infantis. Mesmo os parques que antes eram predominantemente de contemplação, como o parque 13 de Maio, hoje têm outras funções, atendendo a uma grande diversidade de lazer, tanto esportivas quanto culturais.

Por esse motivo, é preciso que o mobiliário urbano dos espaços públicos, incluindo as placas informativas, seja projetado buscando responder às necessidades de uso da população destinatária. Deve-se levar em conta tamanho, formato e localização, evitando barreiras físicas de forma a permitir acessibilidade integral. Quando o projeto não se adequa aos usuários, o mobiliário urbano é escassamente utilizado ou então é mal utilizado, sofrendo riscos de vandalismo. Além disso, é preciso que o mobiliário urbano se integre harmonicamente à paisagem dos espaços públicos. A exemplo disso, vemos aqui a falta de critérios na localização da placa da pista de cooper no parque da Jaqueira (Figura 2), cuja localização não está adequada aos parâmetros de visibilidade e legibilidade, como também se situa dentro do canteiro de uma árvore secular.

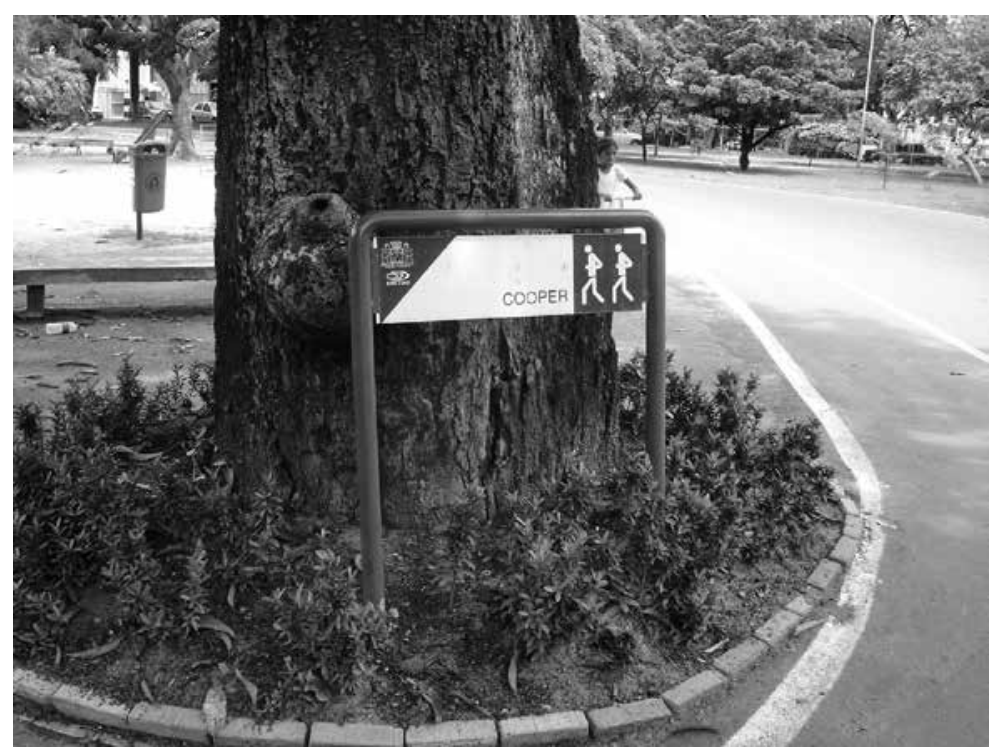

Figura 2: Placa localizada no canteiro de árvore secular - Parque da Jaqueira Foto: Margarida Correia Lima, 2006

\section{COMUNICAÇÃO}

A expansão acelerada e contínua do tecido urbano de nossas grandes cidades e as necessidades de transporte têm acarretado desfiguração dessas urbes, no domínio da comunicação visual. Uma explosão de imagens, símbolos e signos perpassam o labirinto de diferentes estilos arquitetônicos que agridem a paisagem urbana. No dizer de Nojima (1999, in CERBINO, 2000, p. 295): "A cidade é um espaço de comunicação onde o indivíduo se orienta e se move. E, não obstante, todas as transformações, é nas configurações das ruas, das praças, dos lugares, que a cidade se caracteriza." 
E como observa o mesmo autor (2000, p. 295): "... é nesta configuração que se percebem as relações espaciais e temporais que se desenrolam no campo do design gráfico, no qual discurso e imagem configuram-se neste processo e se inserem no imaginário social..." "... a visualidade encontrada nas ruas é uma transcrição de sua construção simbólica... e a prática do design opera como agente transformador da história material e cultural de uma determinada formação urbana."

A cidade é o pólo das construções simbólicas, ou seja, das marcas ou sinais que narram a história não verbal, perpassada por imagens e "máscaras", as quais visualizam conjuntos de valores, hábitos, usos e crenças que, ao longo do tempo, nutrem o dia a dia nos espaços urbanos.

Muitos dos agentes e instituições (privadas e públicas), presentes e atuantes na cidade expressam seus discursos na linguagem gráfica do design: empresas de diferentes setores, como as financeiras e midiáticas, por exemplo, exibem suas marcas nas ruas, nos parques e praças, nos edifícios, utilizando placas, letreiros, etc., - todos procurando transmitir algum tipo de mensagem, para diferentes públicos.

Ferrara (1993, p. 280) constata que a cidade contemporânea "... esvazia-se de manifestações culturais que tinham a multidão e o indivíduo como personagens que expressavam suas emoções em público". E Cerbino (2000, p. 296) explica: "Este esvaziamento é percebido através da mudança da própria imagem da cidade, na medida em que as transformações desses espaços ocorrem de forma cada vez mais veloz e acentuada"; "...os atores urbanos constroem lugares no espaço que representam marcas diferenciais de apreensão da cidade."

Nesse contexto, Cerbino (2000, p. 298) questiona-se: "... qual a relação entre design, cultura e cidade?" E responde: "Entendendo o design como uma atividade que configura objetos de uso e sistemas de informação e, como tal, incorpora parte dos valores culturais que a cerca, tais objetos são a materialização dos ideais e das incoerências da sociedade, além de uma das manifestações culturais. $O$ design participa, assim, da criação cultural como uma práxis que confirma, ou questiona, a cultura de uma determinada sociedade, expressando suas contradições e sendo tão perfeito ou imperfeito quanto ela."

A linguagem gráfica, portanto, é um veículo de comunicação do pensamento que rege as grandes empresas e o Estado, que decidem e manipulam, de algum modo, as direções da sociedade, por meio de outdoors, imprensa, etc, e, atualmente, no uso cotidiano de novas tecnologias da informação.

O design se apoia na ergonomia informacional para elaborar sistemas de informação, que transmitam, aos usuários dos espaços livres públicos, os elementos de orientação de que necessitam - por meio de meios físicos variados, permanentes ou transitórios: placas, sinais, displays, banners, mapas, equipamentos eletrônicos, etc.

\section{ERGONOMIA INFORMACIONAL}

Na ergonomia informacional o importante é a comunicação, a forma como a mensagem é transmitida e a maneira como o usuário responde aos estímulos do ambiente. 
Nesse trabalho considera-se intervenções de design como organização espacial das informações direcionadas ao visitante e integradas ao meio ambiente. A comunicação ambiental fornece a informação necessária para definir os destinos desejados, incluindo os sistemas de signos e as referências arquitetônicas.

Projetos de sistemas de informação devem superar diferenças culturais para proporcionar elementos de linguagem visual acessíveis ao maior número de usuários. Dessa forma, procura-se promover a elevação da qualidade de vida da sociedade proporcionando-lhe informações precisas, ou seja, garantir o acesso aos espaços livres públicos significa avançar para uma sociedade inclusiva.

É importante ressaltar que nos projetos de sistemas de informação para os parques e praças é necessário evitar o uso excessivo de placas e indicações, que acabaria por confundir o usuário com uma pletora de informações, além de provocar a poluição visual da paisagem.

Nas observações ergonômicas, percebeu-se reduzida presença de "pessoas com necessidades especiais" nos parques e praças. Acredita-se que, com as preocupações de acessibilidade e de mobilidade nos projetos hoje executados, esse esvaziamento seja minimizado. A colocação de sistemas de informação nos parques e praças, sobre vários aspectos da cultura da cidade, deverá ser um incentivo para seu uso mais intenso.

"A acessibilidade engloba dimensões físicas e sociais e trata da possibilidade dos indivíduos terem acesso e fazer uso de um ambiente, de um equipamento, ou ambos, de maneira independente. Para tanto se faz necessário o acesso à informação sobre as atividades e os locais onde estas se desenvolvem, a possibilidade de deslocamento com segurança e conforto, e a possibilidade de utilização destes ambientes e equipamentos, sem conhecimento prévio acerca de seu funcionamento. Em resumo, "é principalmente através da informação e da mobilidade - movimento de ir e vir - que o indivíduo participa dos lugares e das atividades e estabelece contato com as demais pessoas, ou seja, exerce seu direito de cidadania." (DISCHINGER, 2001 apud BINS ELY et al, 2002).

Os espaços urbanos que contêm projetos de ergonomia e de design focados nos usuários, quando levam em conta valores e percepções sensoriais e culturais dos grupos sociais aos quais se destinam, necessariamente, são utilizados com mais eficiência pelos usuários.

Verifica-se a necessidade de promover a inclusão de todos os cidadãos, por meio de estudos sobre a compreensibilidade e a usabilidade de sistemas de informação relacionados à linguagem visual, verbal e icônica, considerando as habilidades e limitações dos usuários, como o uso de mapas táteis (Figura 3) dirigidos às pessoas portadoras de deficiência visual e com baixa visão, por meio de informações em Braille com diferenças de textura e cor.

Em quase todos os parques e praças pesquisados havia inexistência de mobiliário de sinalização e também mobiliário contendo informações culturais, de segurança, de preservação dos bens públicos e/ou de informações sobre o entorno. As placas, 


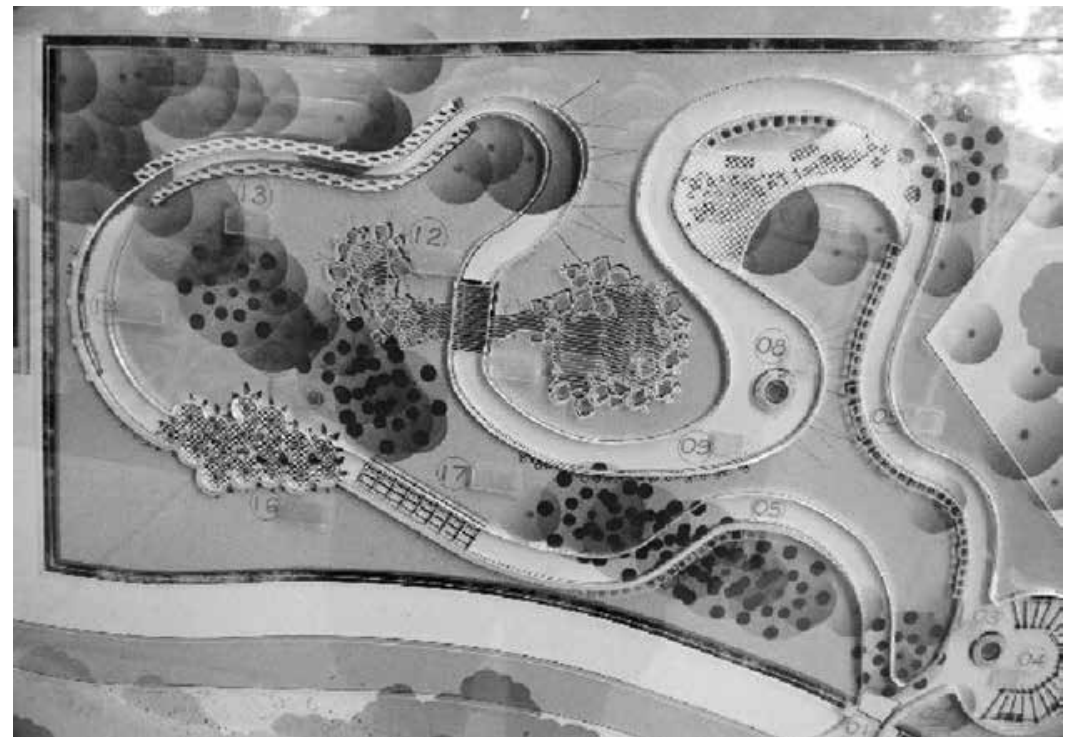

Figura 3 - Mapa tátil Jardim das Sensações, Curitiba PR

Foto: Laura B. Martins, 2009

quando existentes, orientam as saídas, mas não orientam devidamente os serviços e as atividades do parque e/ou da praça. No percurso interno não foi encontrada nenhuma placa de continuidade às informações contidas nas placas de entrada.

As informações buscadas tratam de: alertas sobre possíveis acidentes com as crianças que acontecem com frequência, informações de segurança, ou seja, como proceder diante de um roubo ou acidentes, sobre a história da cidade, do parque/praça e edificações do entorno, sobre a vegetação, comportamentos e usos/localização espacial, sobre os autores dos monumentos, relação dos artistas com a cidade.

Os espaços públicos de representação constituem parte da cidade. E é na paisagem urbana que estão as áreas de preservação e de proteção do patrimônio histórico-cultural, como testemunhos da origem e do desenvolvimento do espaço livre público. A preservação do patrimônio (histórico, cultural, ambiental e paisagístico) condiciona melhor qualidade de vida da população, pois a preservação da memória é também uma importante demanda social. Constitui, assim, uma atividade de interesse urbano definidora das funções sociais da cidade e do bem-estar coletivo.

Acredita-se que muitas das atitudes de desrespeito ao patrimônio público, a exemplo do baobá localizado na praça da República e do marco de entrada do parque 13 de Maio devam-se à falta de sistemas de informação sobre comportamentos e usos relacionados à educação ambiental, campanhas educativas, especificamente sobre preservação dos bens públicos e de outras informações importantes que levem a uma maior integração das comunidades com esses espaços (Figuras 4 e 5).

A informação no espaço público, a natureza pública de seu conteúdo tem por base educar o público: em sua segurança, comodidade, orientação no movimento, interação, cultura urbana, e ainda para outros interesses do público como o da identidade dos locais, atendendo à função simbólica da comunicação.

A cultura urbana da comunicação tem um traço de cidadania devido à liberdade de expressão no espaço público, e também porque se relaciona com valores do co- 

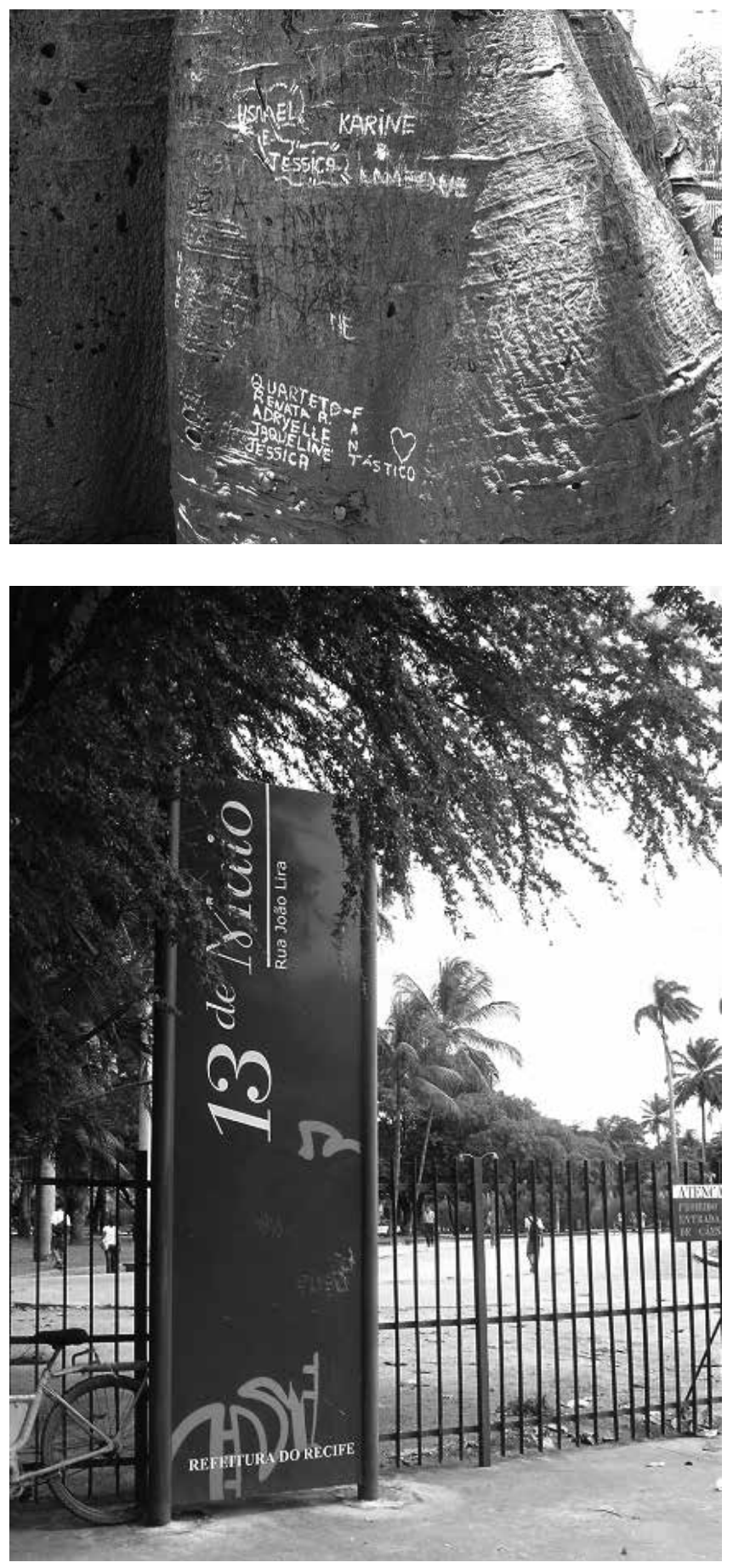

Figura 4: Árvore baobá Praça da República - Árvore secular com pichações Foto: Margarida Correia Lima, 2006
Figura 5: Marco de entrada do parque 13 de Maio Marco de entrada do parque com pichações Foto: Margarida Correia Lima, 2006

letivo, como a interação social e a manifestação política. Ainda com a possibilidade de poder desfrutar da paisagem urbana, reconhecida como um direito de todos, um valor urbano em si mesmo.

A ausência das placas indica que a informação não faz parte do planejamento dos espaços públicos e isso contribui para o mau uso do local, depredações, falta de conforto e insegurança dos usuários. 


\section{A INFORMAÇÃO NO PARQUE 13 DE MAIO E PRAÇA DA REPÚBLICA}

A pesquisa visou identificar quais tipos de informação já foram e/ou estão sendo implantados em programas de requalificação das cidades, na recuperação desses espaços livres públicos de convivência e tipos de informação que precisariam ser introduzidos para atender às demandas dos frequentadores.

Nesse contexto foram escolhidos, para o estudo empírico, o parque 13 de Maio e a praça da República, espaços com grande diversidade sociocultural, por onde circulam pessoas de todas as idades, com níveis culturais e educacionais diversos e com atividades variadas e interesses distintos. A história urbanística mostra a relevância desses espaços públicos do centro da cidade e isso influenciou decisivamente nessa escolha.

No parque 13 de Maio a sinalização era insuficiente, diante das necessidades dos usuários que precisam, em pontos de bifurcação, de orientações sobre seu posicionamento nas vias internas em relação ao entorno. A praça da República é de uso basicamente contemplativo: pelos componentes de vegetação (árvore baobá - a mais antiga da América do sul; e belas palmeiras); e do projeto paisagístico que agrega os prédios históricos e sedes de poderes públicos do entorno.

questionário com os usuários desses espaços, respondido por 74 (setenta e quatro) transeuntes e pessoas em situação estacionária do parque 13 de Maio e praça da República - os que visitam e os que trabalham nesses locais - e a entrevista com os 11 gestores públicos tiveram como objetivo conhecer sua posição sobre a introdução de sistemas de informação: de orientação espacial, difusão cultural, educação ambiental, preservação dos bens públicos. Ainda se procurou conhecer a aceitação dos órgãos públicos envolvidos. As respostas dos dois universos pesquisados - usuários dos espaços públicos e técnicos/gestores públicos municipais dessa área - revelaram boa aceitação para os vários tipos de informação sugeridos nos questionários. Acredita-se, assim, que o conjunto de opiniões obtido fornece subsídios fundamentais para a extração das diretrizes pretendidas.

Nesse sentido, pode-se afirmar que o planejamento de sistemas de informação a serem locados nos parques e praças, respeitando a vocação de cada logradouro e levando em consideração as necessidades dos usuários, contribui, de forma positiva, para a renovação desses espaços de convivência coletiva.

\section{DIRETRIZES PARA ELABORAÇÃO DO SISTEMA DE INFORMAÇÃO PARA PARQUES E PRAÇAS}

objetivo dessa pesquisa foi criar diretrizes para elaboração de sistemas de informação para os espaços livres públicos a fim de identificar, sistematizar e consolidar tantos dados de conhecimento como elementos práticos e instrumentais que permitam adequar os parques e praças a cada meio, cultura e realidade, como veículos de educação. 
Na abordagem ergonômica de espaços urbanos, ganha relevo o problema da orientação. A orientação é um processo cognitivo que abrange a capacidade dos indivíduos de situarem-se mentalmente e fazerem deslocamentos em uma dada situação física. A orientação depende das informações disponíveis no ambiente e da habilidade dos indivíduos para perceberem e servirem-se de tais informações.

objetivo dessa abordagem, nos requisitos recomendados nas diretrizes, é facilitar o acesso dos idosos e dos portadores de necessidades especiais às informações, de modo a diminuir ou eliminar as barreiras arquitetônicas, urbanísticas, informacionais, e até mesmo sociais, nos espaços livres públicos à sua participação em atividades culturais, educativas, de lazer, entre outras.

Essa proposta é baseada na metodologia de análises sistêmicas do sistema homem-tarefa-máquina, de Morais e Mont'alvão (MORAES E MONTA'ALVÃO, 2000, p. 21) que define, na intervenção ergonomizadora, a etapa da apreciação ergonômica. Nesse caso, a etapa exploratória compreende o mapeamento dos problemas ergonômicos dos parques e praças, que consiste na delimitação dos problemas ergonômicos - informacionais, cognitivos, comunicacionais, de acessibilidade e acidentários.

Foram definidos alguns critérios relacionados ao sistema de informação, com base no referencial teórico pesquisado e na apreciação realizada, para a elaboração do questionário com os usuários de parques e praças. São eles: acessibilidade - o sistema de informação deve ser elaborado de forma a garantir a legibilidade ou eficácia no processo cognitivo para o maior número possível de usuários, para que esses tomem decisões de maneira independente e autônoma; segurança - atributos necessários ao sistema de informação, para que o usuário entre e circule no espaço livre público com conforto e percepção clara do ambiente; utilização - caracterizar as atividades que são exercidas, as necessidades por tipos específicos de informações, atributos necessários ao sistema de informação para torná-lo acessível aos diferentes usuários; orientação - orientação espacial dentro e no entorno do logradouro; funcionalidade - tipos de sistemas de informação que deverão ser elaborados para atender às necessidades dos usuários específicos daqueles espaços - orientação espacial, difusão cultural, educação ambiental, preservação dos bens públicos, história do local e da cidade, etc.

Para elaborar os sistemas de informação, inicialmente, recomenda-se conhecer as necessidades dos usuários, conhecer as disponibilidades orçamentárias, parcerias e programações destinadas e identificar os fatores facilitadores e limitadores da administração. Após esse levantamento deve-se confrontar a visão dos gestores públicos envolvidos com os espaços livres públicos com as opiniões dos usuários.

$\bigcirc$ sistema de informação divide-se em quatro blocos. $\bigcirc$ bloco 1 inclui informações básicas, de orientação de circulação no parque ou praça, de comportamentos e usos, de serviços, de alerta sobre possíveis acidentes e referências sobre o transporte público. O bloco 2 trata das informações histórico-culturais e ambientais, vegetação, projetos paisagísticos e seus autores, monumentos, edifícios históricos no entorno, história do parque ou praça e de seu entorno ou região. $\bigcirc$ bloco 3 inclui eventos do local, da 
região e da cidade, programações. E o bloco 4 trata de campanhas educativas, de educação ambiental, de saúde e de preservação dos bens públicos.

Para se criar sistemas de informações adequados a essas áreas, deve-se atender a uma série de condições, tais como: ajustar o tipo de informação à função do espaço público, às atividades ali exercidas e ao contexto em que ele se insere; considerar a importância de cada elemento com sua referência cultural, histórica, ecológica e turística do parque ou da praça e região circunvizinha, mostrando, em recorte, a história da cidade. É preciso planejar a colocação das informações efêmeras, hierarquizadas, locadas no parque ou praça, integrando-as com as campanhas educativas públicas e privadas ou que tenham ações diretas e práticas no local e evitando a polvição visual com excesso de informações. As características dos parques e praças que façam parte de uma mesma área ou região, que poderão ser tratadas em bloco. Servir-se das novas tecnologias, segundo a especificidade da informação - se permanente ou efêmera. Levar em consideração os interesses dos usuários desses espaços por tipos específicos de informação. Colocar as informações de forma acessível a idosos e portadores de necessidades especiais e em linguagem decodificável pelas crianças. Atentar para a necessidade de traduzir em outras línguas informações essenciais em áreas de grande fluxo turístico.

\section{AÇÃO - GESTÃO PÚBLICA}

Na pesquisa realizada com os usuários do parque 13 de Maio e praça da República ficou evidente que as demandas deveriam se concretizar em projetos de requalificação de parques e praças ou de respostas a outras necessidades mais gerais da comunidade. Mas não existe um canal direto para o recebimento das demandas mais específicas dos usuários. Quando os usuários necessitam de algum tipo de informação direcionada a seu conforto ou segurança, por exemplo, os canais existentes ficam muito distantes para encaminhamento de seus pleitos, dos quais os gestores públicos dificilmente tomarão conhecimento.

É uma situação própria de carência de estrutura de gestão a que se aplica a observação de Milet:

"... no plano de gestão da conservação, fica evidente a importância da implantação de uma base de informação. Ela deve ser concebida de modo a responder aos conceitos e pré-requisitos da conservação, às temáticas e estrutura do plano de gestão, à tomada de decisões e às tarefas cotidianas de controle, monitoramento e difusão das informações."( MILET, V., 2002, p. 125)

Nesse contexto sugere-se criar, em cidades de médio e grande portes, uma coordenação centralizada para os sistemas de informação em parques e praças; colocar os sistemas de informação como prioridade nas políticas públicas; integrar os projetos de sistemas de informação aos projetos paisagísticos dos parques e praças. Outro fator relevante é apresentar, de forma explícita, o regulamento de uso dos parques e 
praças e ainda criar um canal mais direto com os usuários para recebimento de suas demandas diárias.

Para que se materializem com sucesso projetos dessa natureza, é importante, mas não determinante, que se façam presentes condições institucionais, administrativas e de articulação harmônica entre técnicos e planejadores das disciplinas envolvidas no tratamento desses espaços. E que os gestores públicos "comprem" como uma prioridade de ação essa abordagem dos interesses dos usuários, na forma de tratar e qualificar tais espaços, tão significativos para convivência e bem-estar dos cidadãos urbanos: parques e praças.

\section{CONSIDERAÇÕES FINAIS}

Um dos elementos importantes da pesquisa foi a leitura da cidade como sistema. Espaço público, espaço privado, elementos arquitetônicos, históricos, culturais, tecnológicos e informacionais foram considerados aqui como subsistemas de um sistema maior chamado cidade.

O espaço público tem se mostrado de forma mais complexa na vida contemporânea. A cidade não é somente o lugar de abrigo, refúgio e proteção. Ela se faz também aparato de comunicação, de deslocamento, de relação e, igualmente, de veiculação de alguns conteúdos urbanos, tais como - informações publicitárias, com seu caráter político, comercial ou cultural. E são os parques e praças espaços públicos para divulgação de vários tipos de informação.

Assim, sendo a nossa época caracterizada pela comunicação como matriz de organização, de valor e de poder, a comunicação no espaço público terá um significado matricial. A compreensão de novos meios, tecnologias e significados comunicacionais, tem um grande território à sua frente, para experiências de interdisciplinaridade, relacionando esteticamente a experiência no espaço público comunicativo com o espaço público urbano.

Os sistemas de informação de parques e praças deverão estar integrados a outros sistemas de informação. Os sistemas de informações de cidades relacionam diferentes tipos de sinalização como o de transportes públicos, de serviços, de pontos turísticos, de poderes administrativos e precisam ter coerência nas linguagens. Assim, precisam de uma interação que facilite sua leitura e compreensão geral, seja por parte de seus residentes, seja pelos visitantes que ainda não conhecem a cidade.

A partir desse estudo, projetos de sinalização desse tipo poderão ser elaborados com um ganho de qualidade, para cidades como Recife, com várias sinalizações (de transporte, de serviços, turística e outras) - sem um referencial sistêmico que as organize. Daí acontece certa algaravia de linguagens, que pouco contribui para mostrar a cidade, com seus valores culturais, históricos e ambientais.

Um olhar crítico sobre outras situações urbanas provavelmente revelará condições semelhantes, reforçando a idéia da validade das diretrizes formuladas para além da realidade local. 


\section{Bibliografia}

BINS ELY, V. et. al. Sistemas de Informação Ambiental - elementos indispensáveis para acessibilidade e orientabilidade, 2002, Recife. Anais... Recife: 2 AB, 2002.

CASTELLS, M. A sociedade em rede - A era da informação: economia, sociedade e cultura. São Paulo: Paz e Terra, 1999.

CEBRIÁN, I. L. A rede - Como nossas vidas serão transformadas pelos novos meios de comunicação. São Paulo: Summus, 1999.

CARRIÓN, F. M. Espacio público: punto de partida para la alteridad. Espacios públicos y construcción social. Hacía un ejercicio de ciudadanía. Santiago: Ediciones SUR, p. 79-97, 2007. Disponível em: http://works.bepress.com/ fernando_carrion/174. Acesso em: jan. 2011.

CERBINO, A. O espaço urbano: reflexos no design. Rio de Janeiro: Estudos em Design, Article, v. 9, 2000. Edição especial.

FERRARA, L. Olhar periférico: linguagem, percepção ambiental. São Paulo: Edusp, 1993.

MILET, V. Base de informação para as tarefas da gestão. Gestão do patrimônio cultural integrado. Recife: CECl; UFPE, 2002.

MORAES, A.; MONT'ALVÃO, C. Ergonomia conceitos e aplicações. Rio de Janeiro: 2AB, 2000.

SÁ CARNEIRO, Ana Rita. Parque e paisagem, um olhar sobre o Recife. Recife: Universitária da UFPE, 2010.

; MESQUITA, Liana. Espaços livres do Recife. Recife: Prefeitura da Cidade do Recife; Universidade Federal

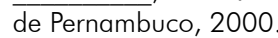


